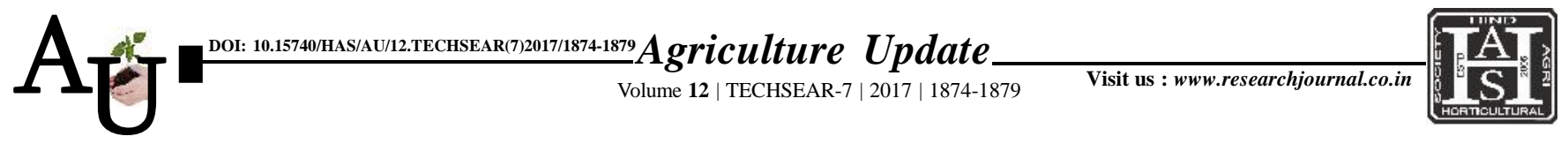

\title{
Research article: Digitizing soil conservation and water harvesting measures in Patapur Micro Watershed using Quantum geographical information system(QGIS)
}

\author{
- IBRAHIM KALEEL, U. SATISHKUMAR, MALLIKARJUNA AND \\ MOHAMMED WASEEM
}

Article Chronicle: Received :

19.07.2017;

Accepted :

03.08.2017

KEY WoRDS :

Soil conservation measures, Water harvesting measures, QGIS

Author for correspondence :

IBRAHIM KALEEL

Department of Soil and

Water Engineering,

College of Agricultural

Engineering, University

of Agricultural Sciences,

RAICHUR (KARNATAKA)

INDIA

Email :

ibrahimkhaleel1075@

gmail.com

See end of the article for

authors' affiliations
SUMMARY : Soil conservation and water harvesting measuresare the most important components for watershed management. In soil conservation and water harvesting planning, efforts were concentrated on suggesting suitable type of soil conservation and water harvesting measures across the slope for both arable and non arable lands which helps in controlling erosion and reducing soil loss directly and in increasing crop yields through additional moisture conservation indirectly. The GIS software sector has developed rapidly over the last ten years. Open Source GIS applications are gaining relevant market shares in academia, business and public administration. The Quantum Geographical Information System (QGIS) is an open source GIS application which is widely used. The conservation measures for the study area are digitized using QGIS software assigning special picturesque icons for individual conservation measures. The conservation measures are suggested based on average annual rainfall $(\mathrm{mm})$ and slope (\%). In this paper we illustrate the use of QGIS software in digitizing soil conservation and water harvesting measures.

How to cite this article : Kaleel, Ibrahim, Satishkumar, U., Mallikarjuna and Waseem, Mohammed (2017). Digitizing soil conservation and water harvesting measures in Patapur Micro Watershed using Quantum geographical information system (QGIS). Agric. Update, 12(TECHSEAR-7) : 1874-1879; DOI: 10.15740/HAS/AU/ 12.TECHSEAR(7)2017/1874-1879. 